\title{
Textiles and the Textile Research and Industries in the Twenty-first Century
}

\section{Alshukur $\mathbf{M}^{*}$}

Department of Textiles, Heriot-Watt University, Edinburgh, UK

The developments in textiles and textile industries are expected to progress of accelerating rates in the new century. Several factors have come to act synergistically to boost these developments. Some of which are new ideas and new technologies, the progress of other areas of science, the collective efforts of multi-discipline researchers, the usage of new tools and methods to study and develop textiles, the speeding up of communication amongst researchers, and the increase in applicability and usage of textiles.

Since the late Twenty Century, researchers in the field of textile industries have seeded this field with plenty of new ideas which may bring even more rapid and rigorous developments. Examples of these ideas may include electro-spinning, high-performance and technical textiles (e.g. membranes, textiles for filtration, functional textiles, E-textiles, carbon fibres, Kevlar fibres, textile-based nano-composites, etc.), smart and intelligent textiles, etc. While the majority of the new ideas originate mainly from nature, many new other are solely ingenious thoughts. Examples may be the invention of smart batteries (such as lithium-ion batteries invented by Sony Corporation in the 1990) driven by the advancement in Material Science. Another example is the extraction of Chitosan and Chitin fibres from sea animals and creatures. Additionally, the invention of conductive polymers in the late 1980s presented a new perspective for further development in electronics and other related industries. It is true that most of these ideas are presented in the last century; however, a complete investigation, application, modification and utilisation of these ideas are yet to progress in the Twenty-first Century. These ideas and inventions were introduced; although they are still incomplete form a commercial and practical perspective. Therefore, the challenge is now to improve these ideas and make them viable and commercially available at reasonable costs and prices. For example, it is necessary to make a continuous electrospun yarn. It is also important to reduce the costs of smart textiles and clothing to make it available to the wide public.

Additionally, the textile industries are benefiting from developments in other fields, in particular material science, nanotechnology, polymer science, chemistry, design, simulation and modelling, surface modification technology, tissue engineering, etc. The recent developments in polymer science have led to the introduction of smart and intelligent polymers and textiles, and conductive yarns, etc. Artificial replacements of human organs or artificial implants have recently appeared in the market following successful progress in tissue engineering. These are being developed continuously to improve their properties, in particular the compatibility with human body, hygienic properties, flexibility, the ability to support living cells and tissue, etc. A new group of active and sensing dyes, such as photo-chromic or thermo-chromic dyes, are being developed corresponding to a similar progress in chemistry and material science.

A promising practice which may boost faster developments in the textile industry is the move toward partnerships with other field of science. Now, it is widely accepted that a multi-discipline research environment may bring useful and important results. In this new environment, a group of several researchers of different qualifications and majors are expected to work together as one team to conduct a research. A textile engineer, a material scientist, a mechanical engineer, a mathematician, a doctor and an electrical engineer may all work together as a team to develop a textile product for medical application. For example, it is becoming a reality to make a special sports suit as a result of such collaboration. This smart sport suit can be made using smart textiles and materials, linked to the GPS system, equipped with tiny devices to monitor the body of the wearer in terms of temperature, blood pressure, heart rate, etc. It also may give the wearer the possibility to be compatible with smart-phones to give instant access to these data. The Georgia Tech Wearable Motherboard ${ }^{\mathrm{TM}}$ is another example of such cooperation and close-linked teamwork.

The application of new research tools and methods may also help promoting the developments in the textiles science and industries. The Design of Experiments now has found its way to application in the textile research and industry following its success in other field of industry [1]. It is important to use such a method for its numerous benefits which the traditional approach of experimenting and manufacturing are unable to offer. Another example is the use of Finite Element Analysis Method to study heat transfer of textile products and garments [2]. Moreover, the usage of Artificial Neural Network may help in modelling or simulating the manufacture process or properties of textile products. Several other numerical methods are being used to study textile composites, nanocomposites, multi-functional composites and materials, e.g. RungeKutta method and Newton-Raphson method to name a few. Another example is the recent introduction of new concepts, tools and methods to assess the quality of fancy yarns $[3,4]$. Such tools may help all parties interested in such expensive and special yarns. Researchers, stylists, fancy yarn manufacturers, traders and fashioners may all rely on such tools to check the quality of such peculiar products.

Even with the emergence of new textiles, the developments in the traditional textiles are still on-going and continuing. The Open Reed Weave (ORW) Technology, comprising weaving and stitching in one process, has been introduced and commercialised by Lindauer DORNIER GmbH. Such a technology has opened the door for more complicated weave structures to be created. This technology promotes the creative element of fabrics and woven structures. It may also produce multi-axial fabrics suitable for technical textiles. The introduction of four-needle-bed knitting machines in the late Twenty Century made it possible to further developing of the traditional knitting process; therefore, making flat or tubular knitted fabrics having so much elaborated patterns. Fancy yarns are being studied in scientific approach,

*Corresponding author: Alshukur M, Department of Textiles, Heriot-Watt University, Edinburgh, UK, Tel: +44-131-449-51; E-mail: malekshukur@yahoo.com

Received May 13, 2014; Accepted May 14, 2014; Published May 17, 2014

Citation: Alshukur M (2014) Textiles and the Textile Research and Industries in the Twenty-first Century. J Textile Sci Eng S2: 005. doi:10.4172/2165-8064.S2-005

Copyright: (c) 2014 Alshukur M. This is an open-access article distributed under the terms of the Creative Commons Attribution License, which permits unrestricted use, distribution, and reproduction in any medium, provided the original author and source are credited. 
rather than only descriptive or statistical studies. Mathematical models are being put forward to account for the manufacturing process and the properties of these special and peculiar types of yarn.

The usage of new textiles, that is called Third Generation Textiles [5], is expanding. It is observed in many new areas of applications; ranging from Space and Space ships and equipment, to medical applications, agriculture, aircrafts and planes, defence, protection, industrial applications, electronics, buildings, etc. The commercial factors, efficiency, suitability and compatibility form the main drive of such an expansion in the fields of application of traditional and new textiles.

Moreover, a new trend has appeared, to encourage more researchers and textile technologists to conduct research in this field, by increasing the readership of state-of-art researches and findings. One important aspect of this trend is the emergence of open-access scientific journals. As an example, the Journal of Textile Science \& Engineering has shown its profound commitment to dissipation of research in the textile industry, by allowing all parties interested to obtain free copies of all articles published with the same journal. Another important aspect of this trend is the usage of the Internet to present the publications in this field. Therefore, this faster and easier method to share ideas, thoughts, findings and results may reduce the efforts of following such advancements.
Finally, it is necessary to stress the importance of the sustainability and ethical issues in relation to these developments. A sustainable approach allows the successive generations to benefits from the Nature, and the ethical issues play their part is ensuring a better life for all parties interested. The environmental issues, recyclability of textiles, ecoprocesses and products, fair-trade practices, health and safety, rational management, and avoiding the over-exploitation of resources may form the key points to be always considered by researches, companies, governments or any other body or organization that supports such researches. The direct benefit through considering these vital issues is sustainable, promising and harmless development.

\section{References}

1. Alshukur M, Fotheringham A (2014) Quality and structural properties of gimp fancy yarns by using the Design of Experiments. J Text Inst.

2. Cimilli S, Nergis FB, Candan C (2008) Modeling of Heat Transfer Measurement Unit for Cotton Plain Knitted Fabric using a Finite Element Method. Text Res J 78: 53-59.

3. Alshukur M (2013) The Quality of Fancy Yarn: Part I: Methods and Concepts Int J Text Fashion Technol 3: 11-24.

4. Alshukur M (2013) The Quality of Fancy Yarn: Part II: Practical Experiments and Application. Int J Text Fashion Technol 3: 25-38.

5. Agarwal BJ, Agarwal S (2011) Integrated Performance Textiles designed for Biomedical Applications. International Conference on Biomedical Engineering and Technology, IACSIT Press, Singapore. 